\title{
MIDAS
}

Museus e estudos interdisciplinares

$8 \mid 2017$

Dossier temático "Objetos e museus: biografias, narrativas e vínculos identitários"

\section{Considerações sobre a biografia da instalação Oh la la,... oh la Balançoire/Microcosmos Tentacular de Susanne Themlitz}

On the biography of Oh la la,... oh la Balançoire/Microcosmos Tentacular by Susanne Themlitz

\section{Cristina Barros Oliveira}

\section{(2) OpenEdition}

\section{Journals}

Edição electrónica

URL: http://journals.openedition.org/midas/1262

DOI: $10.4000 /$ midas. 1262

ISSN: 2182-9543

\section{Editora:}

Alice Semedo, Paulo Simões Rodrigues, Pedro Casaleiro, Raquel Henriques da Silva, Ana Carvalho

Refêrencia eletrónica

Cristina Barros Oliveira, « Considerações sobre a biografia da instalação Oh la la,... oh la Balançoire/ Microcosmos Tentacular de Susanne Themlitz », MIDAS [Online], 8 | 2017, posto online no dia 31 julho 2017, consultado no dia 01 maio 2019. URL : http://journals.openedition.org/midas/1262 ; DOI : $10.4000 /$ midas. 1262

Este documento foi criado de forma automática no dia 1 Maio 2019.

\section{c) (†) ()}

Midas is licensed under a Creative Commons Attribution-NonCommercial-ShareAlike 3.0 International License 


\title{
Considerações sobre a biografia da instalação Oh la la,... oh la Balançoire/ Microcosmos Tentacular de Susanne Themlitz ${ }^{1}$
}

\author{
On the biography of Oh la la,... oh la Balançoire/Microcosmos Tentacular by
}

Susanne Themlitz

Cristina Barros Oliveira

NOTA DO EDITOR

Artigo recebido a 31.03.2017

Aprovado para publicação a 28.06.2017

\section{Introdução}

1 Ainda que a sua origem possa ser relacionada com tendências artísticas que procuraram fugir aos espaços de apresentação institucionais (Bishop 2005), há muito que a instalação deixou de ser uma forma de arte marginal, sendo atualmente uma tipologia comum nas coleções de arte contemporânea, muitas vezes pensada para o espaço do museu. Neste artigo, através da análise do caso de Oh la la,... oh la Balançoire/Microcosmos Tentacular (daqui em diante designada apenas como oh la la), da artista Susanne Themlitz (coleção Caixa Geral de Depósitos) focar-nos-emos nalguns dos desafios que as instalações colocam quando integradas em coleções museológicas, particularmente a forma como a sua variação ao longo do tempo - resultante de fatores diversos - obriga ao desenvolvimento de novas estratégias para a conservação das obras e de diferentes modos de comunicação 
com os públicos. Como analisaremos, a ideia de "biografia da obra" é um ponto de partida muito pertinente neste contexto.

Tendo já sido descrito como um umbrella concept (Mechelen 2006), o conceito de instalação é reconhecidamente difícil de definir, dada a heterogeneidade de obras que têm sido incluídas nesta categoria (Bishop 2005; Mechelen 2006). Contudo, fazendo uma revisão da literatura sobre este assunto é possível identificar algumas das características geralmente associadas à noção de instalação (ver Oliveira 2016). Em primeiro lugar, uma instalação é geralmente constituída por mais do que um objeto/componente, embora deva ser entendida como um todo (Oliveira et al. 1994; Reiss 1999; Rosenthal 2003; Ran 2009). Esta tende a envolver o espetador que entra dentro da obra, e ao qual esta se revela à medida que o último se desloca no seu interior (Reiss 1999; Rosenthal 2003; Bishop 2005; Weyer 2006; Wharton e Molotch 2009; Scholte 2011). Muitas instalações envolvem uma experiência multissensorial (Stringari 1999; Real 2001; Bishop 2005; Weyer 2006; Ran 2009; Scholte 2011). E, por fim, mas não menos importante, os componentes intangíveis têm um papel fundamental, nomeadamente a distribuição espacial dos diversos elementos pelo espaço de exposição, sendo privilegiadas as relações entre os mesmos e o contexto (Real 2001; Weyer 2006).

3 No caso da instalação, a fronteira entre a criação e a apresentação esbate-se, na medida em que a obra só se concretiza realmente no local de exposição, no qual os artistas (tendencialmente) a vêem completa pela primeira vez. Ao distribuir-se pelo espaço, estas obras integram-no em si mesmas, fazendo com que uma alteração no primeiro resulte numa modificação das obras e da sua perceção pelo público. É por isso frequente que, durante o processo de montagem, os artistas trabalhem direta e espontaneamente sobre a instalação, de modo a que esta responda a cada novo espaço (Stringari 1999). Os sucessos e os insucessos tornam-se evidentes apenas no decurso da exposição, podendo levá-los a alterar a obra ao longo do tempo. Por outro lado, a variação de uma instalação pode também resultar de circunstâncias externas, e por vezes aleatórias, que condicionam a sua apresentação e das quais veremos alguns exemplos neste artigo.

4 Para Pugliese e Ferriani (2009), este caráter variável das obras, é intrínseco à instalação, devendo esta ser considerada um «médium em evolução», do qual o acaso e a modificação contínua podem ser parte integrante: «the installation is a practice of art in which chance and continuous modification can sometimes be a poetic element, which cannot be relinquished» (Pugliese e Ferriani 2009, 175).

Refletindo, do ponto de vista da conservação das obras, acerca das alterações que estas sofrem ao longo do tempo, quer no seu todo, quer ao nível dos seus elementos, sobretudo no caso das instalações, Renée van de Vall, Hanna Hölling, Tatja Scholte e Sanneke Stigter, participantes no projeto de investigação New Strategies in the Conservation of Contemporary Art ${ }^{2}$, propuseram uma "abordagem biográfica" ao percurso das obras (Vall et al. 2011). A sua proposta inspira-se em estudos desenvolvidos, particularmente na área da Antropologia ${ }^{3}$, que procuram explorar a forma como os objetos (as suas modificações, as alterações de estatuto e de uso) iluminam determinados comportamentos humanos e relações sociais. As autoras sugerem que as biografias das obras podem ser escritas a diversos níveis. Nestes incluir-se-iam a trajetória, por um lado, dos materiais e elementos da obra e, por outro, da última como um todo, da sua adaptação a diferentes espaços e ainda do conhecimento acerca da mesma e a sua documentação. Esta biografia consistiria, portanto, no conjunto de várias biografias parciais, entrelaçadas, com diferentes inícios, percursos, dinâmicas e finais (Vall et al. 2011), que iluminariam pontos decisivos de 
mudança no percurso da obra, assim como os fatores que justificaram essas alterações, contribuindo, deste modo, para a sua conservação.

6 Como explica Janet Hoskins, investigadora na área da Antropologia, a ideia de traçar a biografia dos objetos tem sido trabalhada de diversas maneiras e por disciplinas variadas (Hoskins 2006). Fazendo um apanhado dos estudos que se têm dedicado a este assunto, Hoskins considera que estes podem dividir-se em dois grupos dominantes. Por um lado, aqueles que se iniciam como uma investigação etnográfica e procuram explorar a forma como os objetos são entendidos pelas pessoas e pelas comunidades aos quais estão ligados, um tipo de estudo que tem sido desenvolvido sobretudo por antropólogos. Por outro lado, aqueles que, na área da história da arte, história e arqueologia, fazem o percurso inverso, interrogando os próprios objetos e tentando fazê-los "falar", ao colocálos num determinado contexto histórico e ligá-los a fontes escritas (como diários, inventários, registos comerciais, entre outros). Embora recorram a metodologias diferentes, ambas as "tendências", definidas por Hoskins, utilizam os objetos como forma de iluminar o seu contexto (histórico, social, entre outros). As mudanças nos objetos, quer sejam físicas ou relativas ao seu estatuto, informam sobre os usos e costumes que os envolvem, os significados que lhes são atribuídos, entre outras (Hoskins 2006).

7 De que forma se integra a proposta de Renée van de Vall e coautoras, que apresentámos anteriormente, nestas duas "correntes" identificadas por Hoskins? Recordemos que esta proposta sugere que a noção de biografia permite acomodar, documentar e esclarecer as mudanças nas instalações ao longo do tempo. Se, por um lado, a utilização de fontes documentais é mais tradicional na área da história da arte, e está habitualmente presente na investigação em torno da conservação de qualquer obra, por outro lado, o facto de se tratar de obras mais recentes permite uma investigação mais próxima das metodologias etnográficas. A investigadora holandesa Vivian van Saaze sugere que se verifica uma aproximação da investigação em torno da conservação de arte contemporânea aos métodos da etnografia, como a entrevista ou a observação participante (ainda que de forma informal) (Saaze 2009). Ou seja, embora as autoras da proposta não explorem esta vertente, pode considerar-se que, em termos metodológicos, a investigação para a construção da biografia de uma obra de arte, no âmbito da conservação de arte contemporânea, se situa entre as duas linhas de investigação propostas por Hoskins (2006), fazendo uso quer das fontes documentais, quer dos métodos mais próximos da investigação etnográfica.

8 Este é o caso da investigação realizada em torno de Oh la la, da artista Susanne Themlitz. Após a sua primeira apresentação, em 2004, na exposição Vidas Imaginárias, na Fundação Calouste Gulbenkian (FCG), a obra foi adquirida pela Caixa Geral de Depósitos (CGD) para incorporar a sua coleção. Cerca de 230 elementos, nos quais se incluem, entre outros, paletes de madeira, bolas de gesso, animais embalsamados, fotografias, plantas, baldes de plástico e uma bicicleta, transitaram da exposição para as reservas da coleção. Nove anos passaram até que a obra fosse exposta novamente. Em 2013 tivemos oportunidade de assistir ao reencontro entre a obra e a artista que, com o apoio da equipa da Culturgest, a montou novamente para a exposição Sentido em Deriva - Obras da Coleção da Caixa Geral de Depósitos, nas galerias da Culturgest, em Lisboa. A biografia desta obra, que aqui se apresenta, constrói-se no cruzamento das informações documentais com aquelas obtidas junto dos diversos intervenientes na vida desta instalação, não só através de entrevistas, mas da observação do processo de montagem da obra e das discussões que estiveram na base de certas decisões. 


\section{Sobre Susanne Themlitz} formação artística na Ar.Co, em 1987, onde estudou desenho e escultura. Concluiu o curso em 1993, contando com um ano de intercâmbio, em 1992, no Royal College of Art de Londres. Em 1995, terminou um MFA (Meisterchüler) na Kunstakademie de Düsseldorf, com uma bolsa da FCG.

10 A artista expõe regularmente desde 1992, tendo realizado a sua primeira exposição individual em 1996. A sua obra é interdisciplinar e foi já vencedora de vários prémios na área do vídeo, desenho e escultura. Para além da coleção da Fundação CGD, o seu trabalho está representado em diversas coleções portuguesas, como a da FCG, Fundação de Serralves, Museu de Arte Contemporânea de Elvas e Museu de Arte Contemporânea do Funchal, entre outras, e estrangeiras como a do Museo Extremeño e Iberoamericano de Arte Contemporáneo ou a do Museo de Arte Moderno y Contemporáneo de Santander y Cantabria.

11 Através da utilização de diversos media, usados individualmente ou misturados em instalações, Themlitz cria «universos carregados de onirismo - de fantasia, de maravilhoso, de fantástico» (Wandschneider 2006, 3), povoados por seres ao mesmo tempo estranhos e familiares. Personagens que, de acordo com o curador Miguel Wandschneider:

[...] emergem do encontro entre a sua imaginação e um imaginário que nos é a todos familiar, que faz parte da nossa memória cultural, um imaginário que se filia nas categorias do maravilhoso e do fantástico e que encontrou, ao longo dos séculos, terreno fértil de expressão em vários géneros da literatura (erudita ou popular) e do cinema, na mitologia, nas estórias infantis. (Wandschneider 2006, 5)

O curador realça que estas personagens, juntamente com outros elementos facilmente identificáveis (como aviões, brinquedos, entre outros), «ficcionam este mundo em que entramos como se fôssemos espectadores dentro de um filme em que tudo se tornou estático e o movimento apenas a nós, espectadores, pertencesse» (Wandschneider 2006, 4).

Rosengarten (2008) refere que Themlitz sempre se interessou na sua obra por uma «condição criatural»:

Com a minúcia de uma etóloga e a frieza aparente de uma taxinomista, a artista tem-se dedicado, em textos copiosos que acompanham as suas prolíficas instalações de seres híbridos ou liminares, a classificar as características inerentes destes. E, com a imaginação empática de uma contadora de histórias, a insuflar-lhes uma vida complexa. (Rosengarten 2008, 2)

Se em obras como Galeria dos Solitários Carrancudos e Ensimesmados (2001) estes seres se materializam em pequenas esculturas de barro, noutras, como em o Estado do Sono (2006), Themlitz cria figuras em tamanho natural (próximas da escala do espectador) cujos corpos, construídos com materiais diversos como funis, tubos de alumínio ou baldes de plástico, entre outros, são cobertos com roupas comuns. Noutros casos, é o próprio corpo da artista que serve de suporte à manifestação destes seres, como em Solitários $e$ Inofensivos (2001) ou Trigémeos Inofensivos (2000), nos quais a fotografia é usada de forma a distorcer o referente - o corpo da artista - com o uso de longa exposição e máscaras, criando figuras de contornos indefinidos, ou perspetivas que alteram as proporções do 
corpo. Themlitz conta que, apesar de já ter tentado utilizar outras pessoas nas fotografias, acabou por perceber que, com várias fisionomias, se «perdia o sentido de definir e complementar a etologia de uma espécie» (Medeiros 2002, s/p). A artista refere que o importante não é reconhecer a pessoa retratada, mas sim «a espécie com os seus comportamentos sugeridos pela pose, pelo olhar, pela perspetiva escolhida, dentro da tradição do retrato» (Medeiros 2002, s/p).

15 Já em obras como Oh la la deparamo-nos com os vestígios de um destes seres. Ele ou ela «Não está. Ou terá desaparecido». ${ }^{4}$ Restaram os «monumentos enevoados», «um jardim que ele habitou ou se fez habitar», «os ovos gigantes ou planetas minúsculos, os «fósseis de retratos ausentes», a «casota reciclada», «os órgãos espumosos», a «bicicleta voadora», a «sela viajante», as «couves e outras plantas braçudas». Ele «colecionava estados», refere a artista, ou talvez estes o tenham invadido. ${ }^{5}$

\section{0 percurso da obra}

Oh la la foi criada por Themlitz entre 2003 e 2004 com vista à participação na exposição Vidas Imaginárias, comissariada por Jorge Molder. Esta instalação esteve patente na galeria de exposições temporárias da sede da FCG, entre novembro de 2004 e janeiro de 2005.

No respetivo catálogo, Jorge Molder, refere que o título da exposição foi um «pedido de empréstimo» ao livro homónimo do escritor francês Marcel Schwob (1867-1905) (Molder 2004, 5). Como explica o comissário, o título concentra em si, não só um pedido de empréstimo, mas também «um ponto de partida, ou melhor ainda, um pretexto e, também, uma homenagem» a este escritor que, no seu livro, reuniu um conjunto de vidas imaginárias ou imaginadas, acreditando que o biógrafo não tem que se preocupar com o verdadeiro, mas criar no meio de um caos de traços humanos (Molder 2004, 5).

18 A exposição Vidas Imaginárias, por sua vez, reuniu os artistas Patrick Corillon (n. 1959), Emilia e Ilya Kabakov (n. 1945; e 1933) e Susanne Themlitz, que desenvolveram personagens no seu trabalho e que, para Molder, «se não cabem na definição stricto sensu de biógrafos, podem bem ser acolhidos nesta quase missão schwobiana» (Molder 2004, 5). É neste contexto que encontramos Oh la la com os seus vestígios de uma vida que está ausente do espaço.

19 Tal como noutras obras de Themlitz, é convocada uma estética rural, com recurso a materiais de aspeto usado e envelhecido. Aqui os objetos ganham novas funções: garrafões de água cortados e baldes servem agora de vasos a plantas, velhas paletes unem-se para formar abrigos. Catos, couves, palmeiras, musgo e caracóis completam o quadro campestre que, no entanto, pela presença de vestígios e "monumentos" estranhos, depressa se transforma noutra coisa. São os vestígios de uma vida que não entendemos completamente.

20 De acordo com a artista, o espaço da FCG onde a peça foi mostrada e, particularmente, a ligação com o jardim, através das paredes envidraçadas, inspirou a criação de uma relação interior-exterior, prolongando o jardim para a sala de exposições. Nas palavras de Themlitz: «prolongá-lo por um habitante ausente, somente com vestígios». ${ }^{6}$

21 A forma rudimentar de uma casa «obsessivamente reiterada no trabalho de Themlitz» (Rosengarten 2008, 10), surge nesta obra, por um lado, na sua forma de local seguro, de armazenamento e abrigo - uma casota construída com paletes - e, por outro, apoiada em estacas, transformada num espigueiro ou num posto de observação. $O$ último "vigia" a 
entrada (ou uma das entradas) da sala enquanto a primeira pontua o seu extremo mais longínquo.?

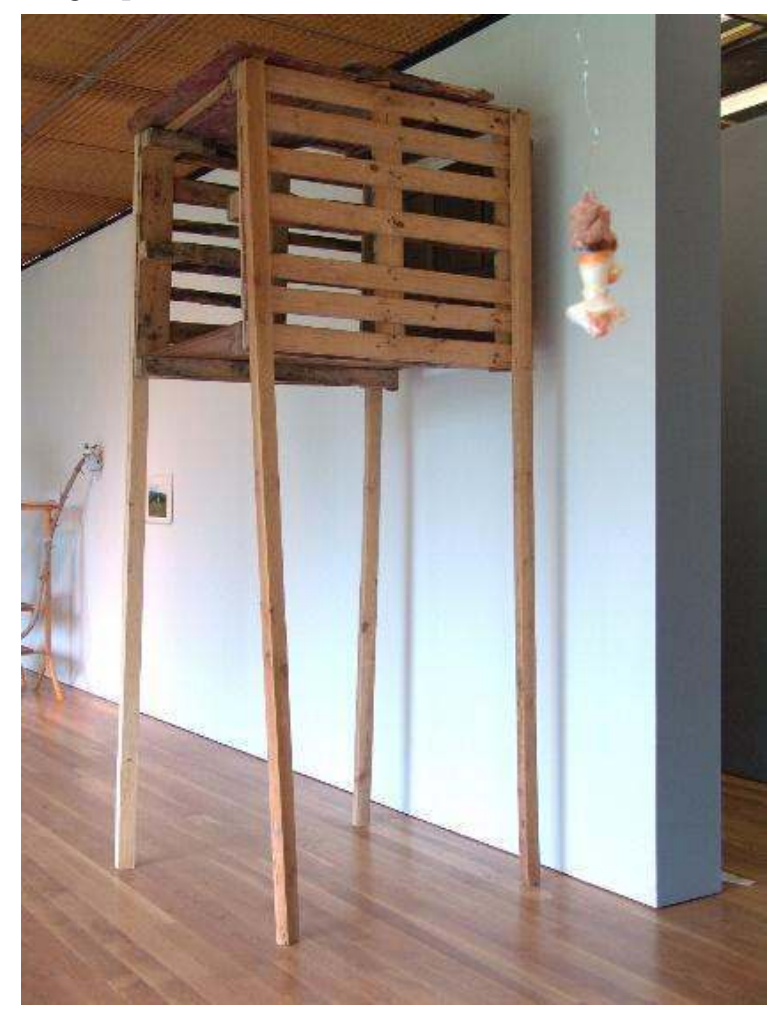

Fig. 1 - Oh la la na exposição Vidas Imaginárias, sede da FCG, entre novembro de 2004 e janeiro de 2005. Elemento referido como "posto de observação" no texto.

Cortesia da artista (c) Susanne Themlitz

Depois de passar o "posto de observação" (a casota apoiada em estacas, fig. 1), entrando na sala, deparamo-nos com uma série de "conjuntos" que se distribuem pelo espaço. Uma bicicleta com "asas", construídas com canas, apoia-se sobre um andaime amarelo. Uma escultura de um caracol encima uma coluna construída com alguidares verdes, vermelhos e azuis apoiados sobre uma botija de gás. Em frente, uma superfície espelhada curva-se, encostada à parede, distorcendo o reflexo da coluna (fig. 2). 


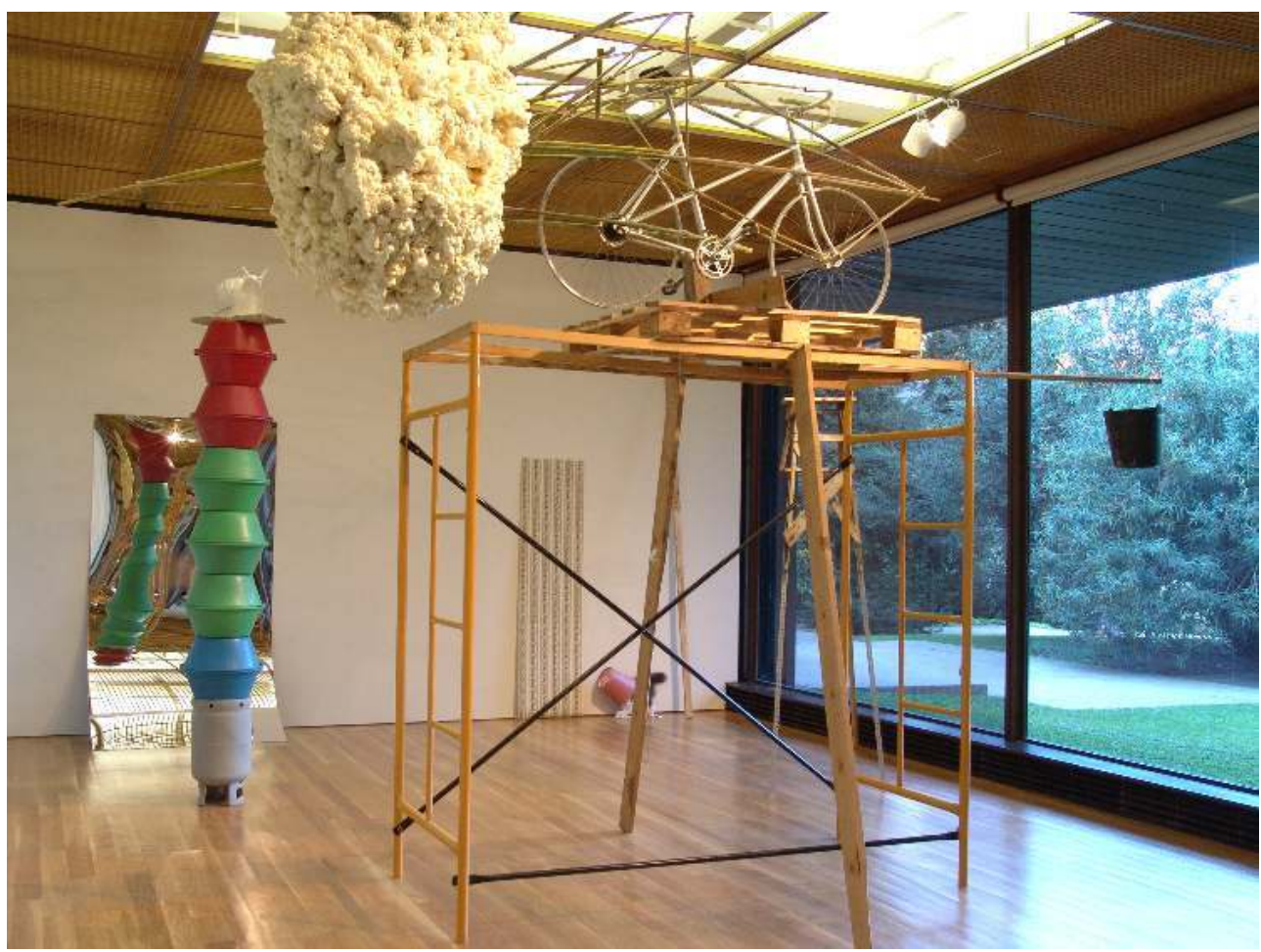

Fig. 2 - Oh la la na exposição Vidas Imaginárias, sede da FCG, entre novembro de 2004 e janeiro de 2005. Na imagem vê-se, à esquerda, uma escultura de um caracol sobre uma coluna construída com alguidares verdes, vermelhos e azuis apoiados sobre uma botija de gás. Esta está em frente a um espelho que se encosta sobre a parede, curvando. À direita, na mesma imagem a bicicleta com asas, construídas com canas, apoiada sobre um andaime amarelo.

Cortesia da artista (c) Susanne Themlitz

Uma escultura de um coelho com um casaco vermelho e um cesto às costas - cuja ponta do focinho foi tapada com uma substância amarela de aspeto esponjoso (poliuretano) apoia-se sobre barrotes de madeira (fig. 3). 


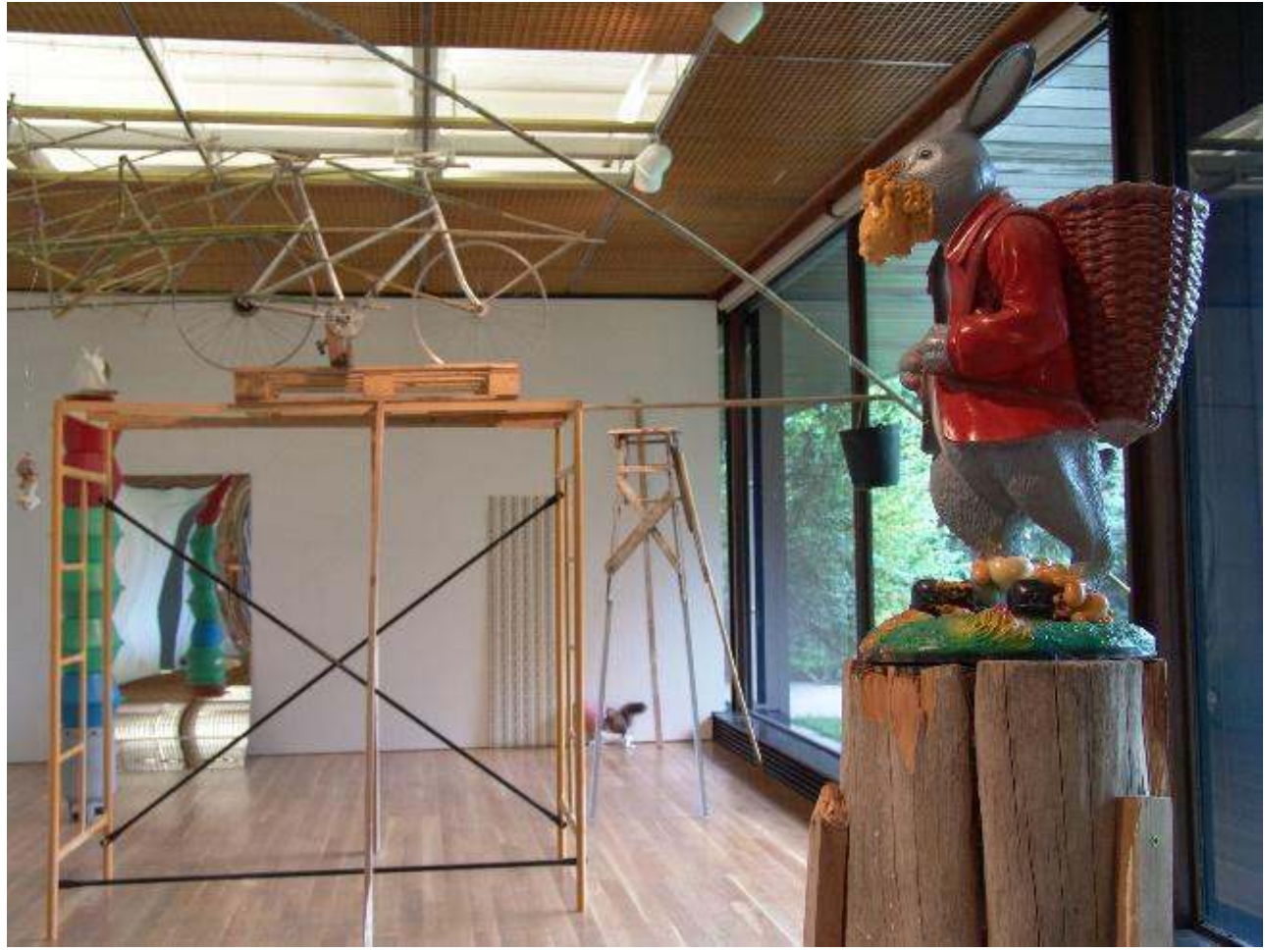

Fig. 3 - Oh la la na exposição Vidas Imaginárias, sede da FCG, entre novembro de 2004 e janeiro de 2005. Em primeiro plano vê-se uma escultura de um coelho com um casaco vermelho e um cesto às costas - cuja ponta do focinho foi tapada com uma substância amarela de aspeto esponjoso (poliuretano) e que se apoia sobre barrotes de madeira.

Cortesia da artista @ Susanne Themlitz

24 Um andaime amarelo, com portadas de madeira a servir de prateleiras, faz de expositor a moldes de cabeças em gesso (em baixo relevo), musgo, caracóis, uma fotografia de uma floresta, uma cafeteira antiga e uma estrutura de metal semelhante a uma escada (fig. 4). 


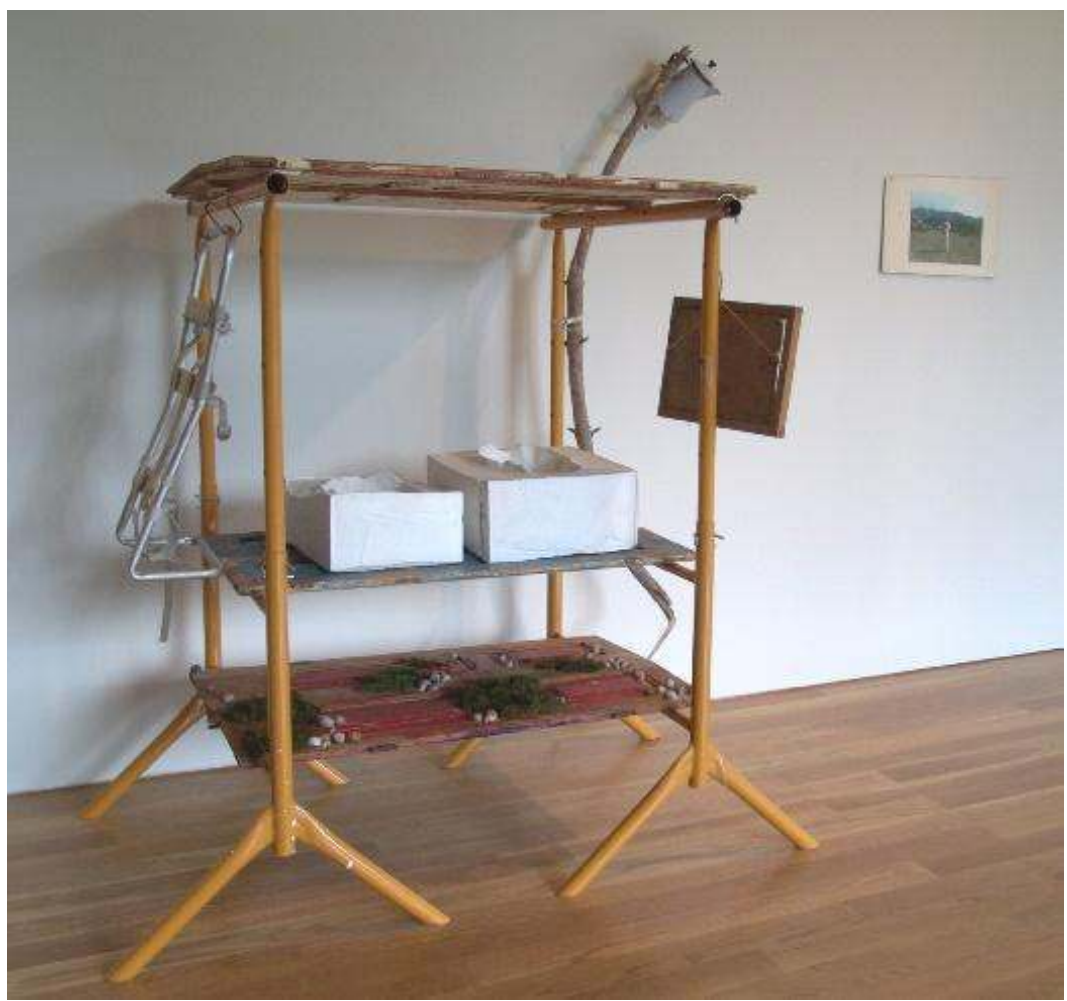

Fig. 4 - Oh la la na exposição Vidas Imaginárias, sede da FCG, entre novembro de 2004 e janeiro de 2005. Na imagem vê-se um andaime amarelo, com portadas de madeira a servir de prateleiras, nas quais se expõem moldes de cabeças em gesso (em baixo relevo), musgo, caracóis, uma fotografia de uma floresta, uma cafeteira antiga e uma estrutura de metal semelhante a uma escada. Ao lado, uma fotografia de um humanóide com um fato de macaco branco que segura no colo um cão.

Cortesia da artista (c) Susanne Themlitz

Ao lado, uma fotografia de um humanóide com um fato de macaco branco e uma cabeça estranha - que parece o cruzamento entre uma cabeça humana e uma cabra - que segura no colo um cão. Uma sela, óculos de proteção, um caixote, uma couve e uma jarra de plástico azul elevam-se sobre três ripas de madeira (fig. 5). Uma marta embalsamada com um balde na cabeça, papel de parede, barrotes de madeira, canas com cogumelos na ponta de fios de nylon, um escadote e elementos granulosos amarelos suspensos no teto (poliuretano) completam o quadro. 


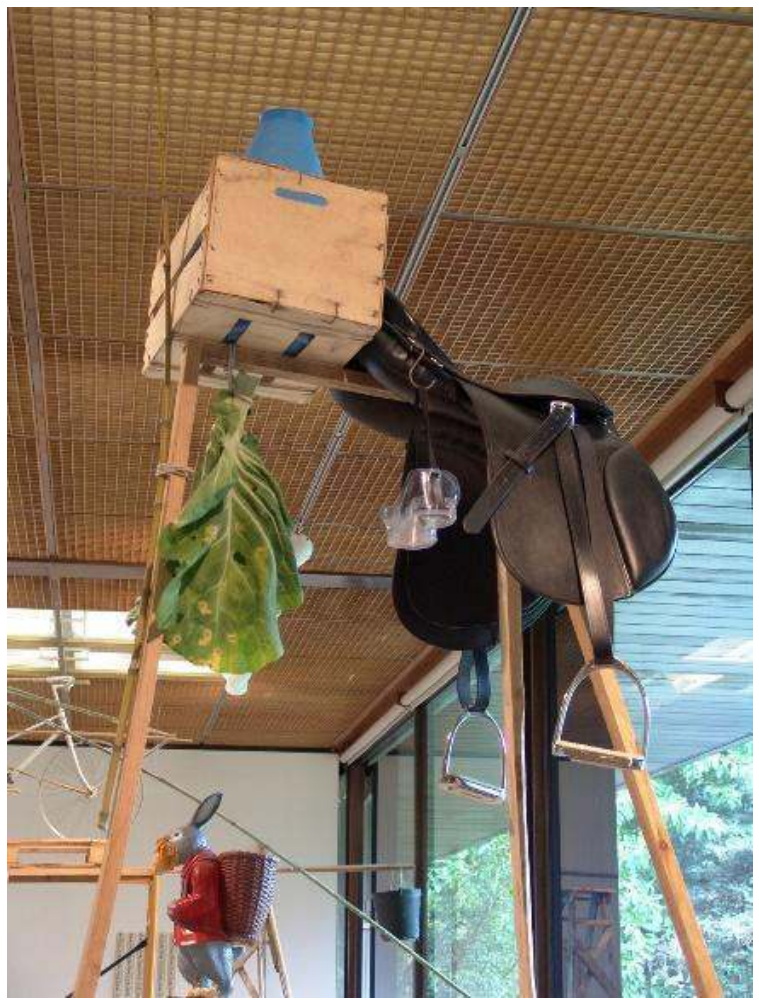

Fig. 5 - Oh la la na exposição Vidas Imaginárias, sede da FCG, entre novembro de 2004 e janeiro de 2005. Elemento constituído por uma sela, óculos de proteção, um caixote, uma couve e uma jarra de plástico azul elevam-se sobre três ripas de madeira.

Cortesia da artista (c) Susanne Themlitz

Chegamos enfim à casota de paletes, não sem antes passar por outro andaime onde encontramos novamente moldes de cabeças em gesso, desta vez acompanhados por plantas (couves e catos) cultivadas em vasos, baldes e garrafões. $O$ topo da estrutura é pontuado por uma imponente escultura de um javali (fig. 6). 


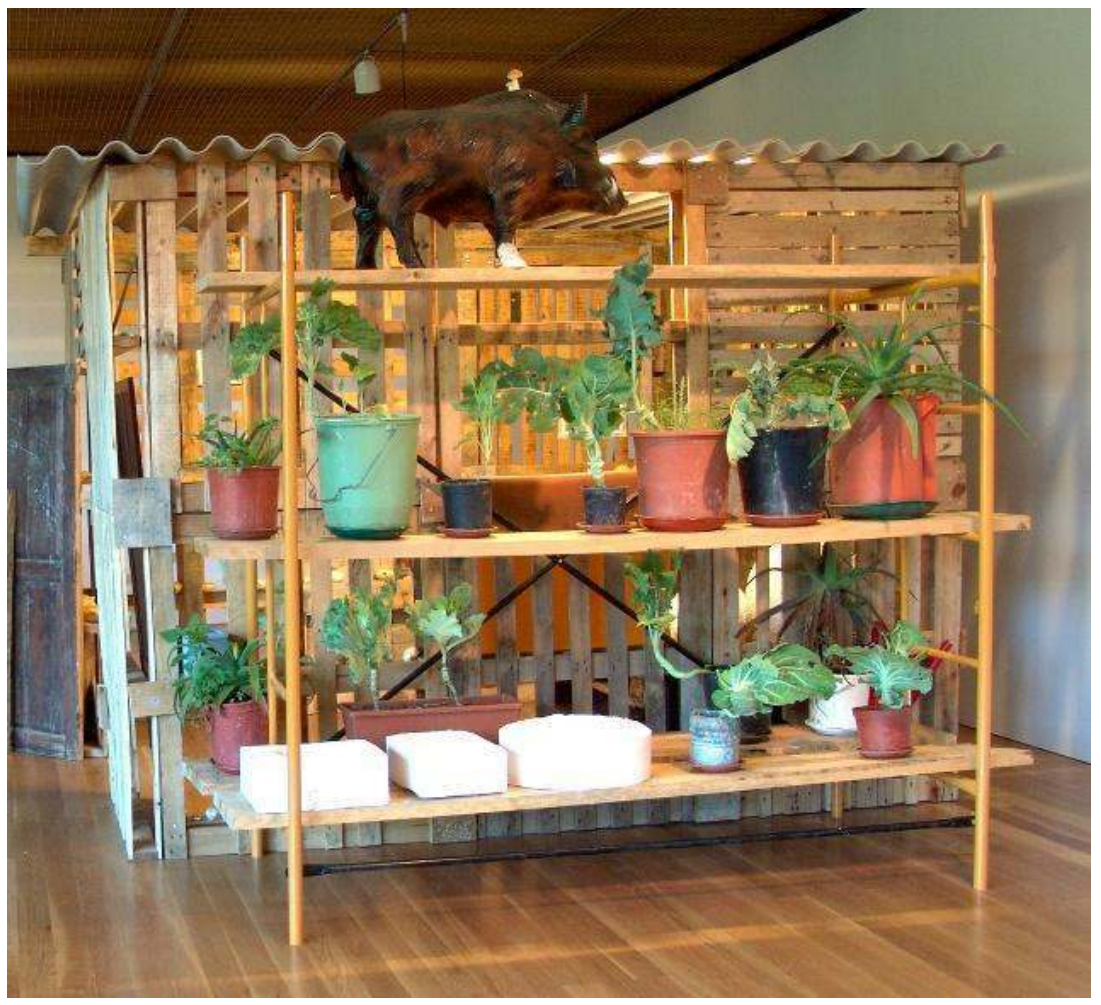

Fig. 6 - Oh la la na exposição Vidas Imaginárias, sede da FCG, entre novembro de 2004 e janeiro de 2005. Vista de um dos lados da "casota de paletes" ao qual se encosta um andaime amarelo onde encontramos moldes de cabeças em gesso, desta vez acompanhados por plantas (couves e catos) cultivadas em vasos, baldes e garrafões. No cimo a escultura de um javali.

Cortesia da artista (c) Susanne Themlitz

Contornamos a estrutura chegando à entrada da casota, marcada por uma velha porta de madeira aberta e por algumas plantas no chão, do lado esquerdo. No seu interior, encontramos um novo mundo. 


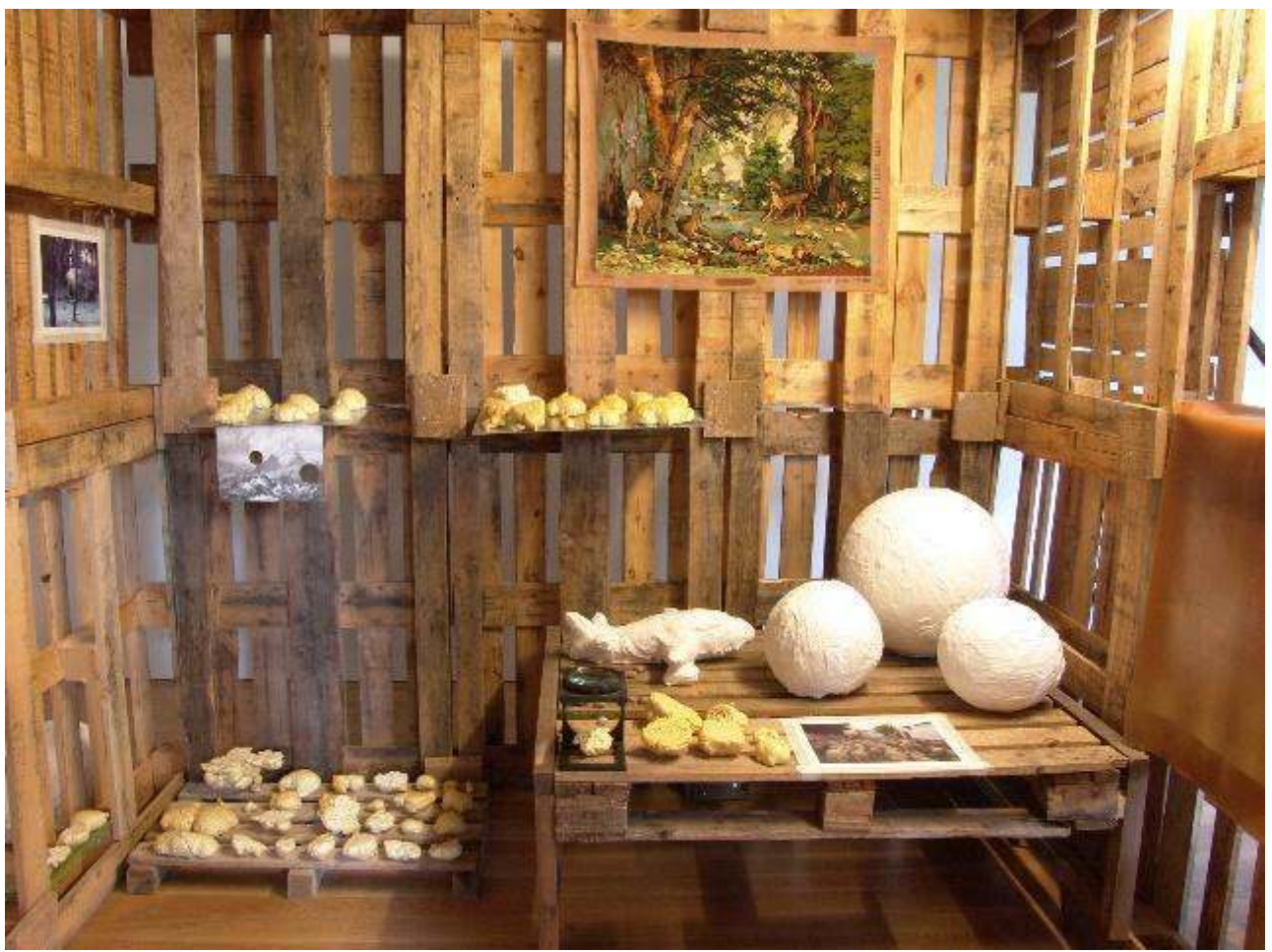

Fig. 7 - Oh la la na exposição Vidas Imaginárias, sede da FCG, entre novembro de 2004 e janeiro de 2005. Interior da "casota".

Cortesia da artista (c) Susanne Themlitz

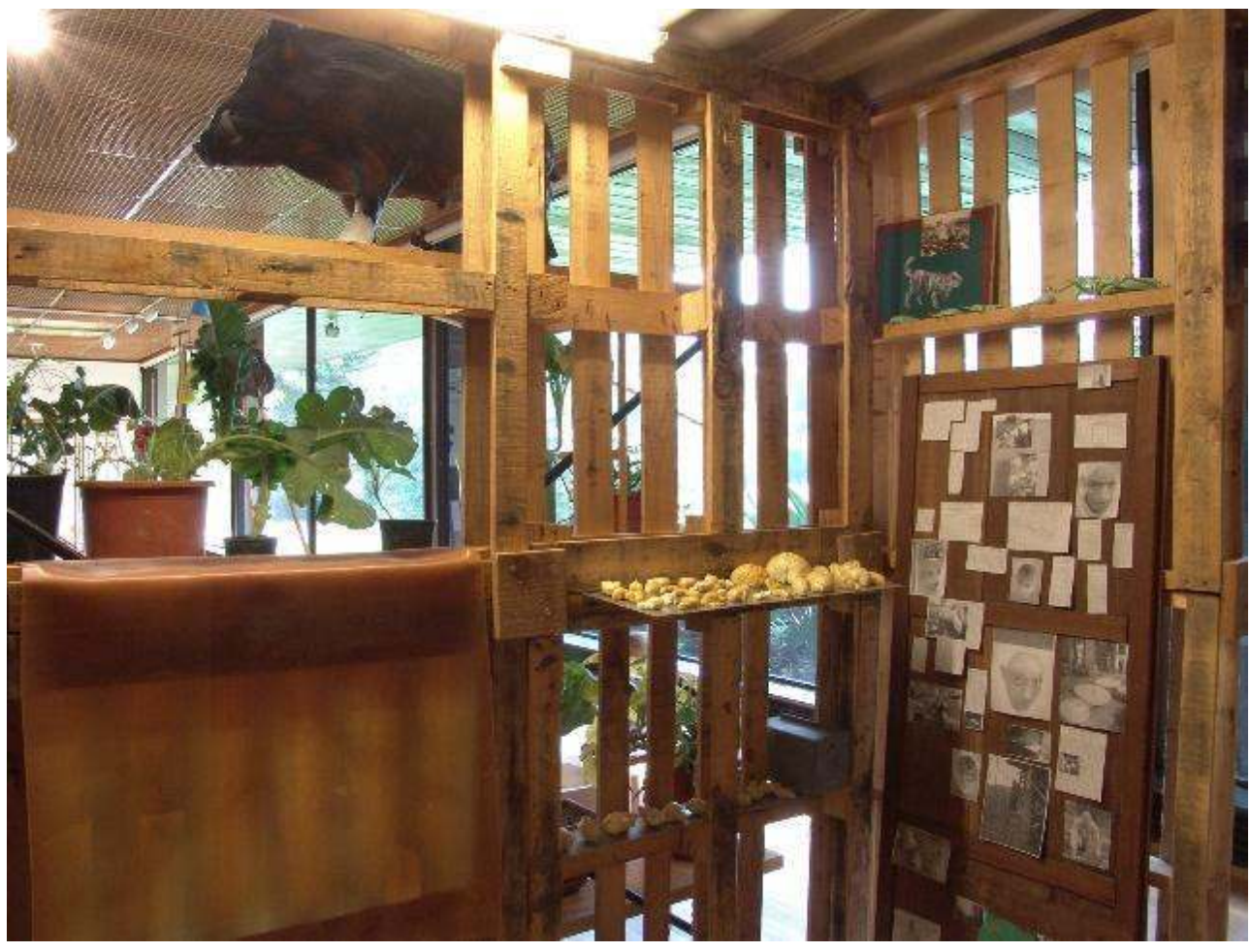

Fig. 8 - Oh la la na exposição Vidas Imaginárias, sede da FCG, entre novembro de 2004 e janeiro de 2005. Interior da "casota".

Cortesia da artista (c) Susanne Themlitz 
Por todo o lado, pequenas estruturas amorfas, de tom amarelado. Têm um ar esponjoso (embora enrijecido). De certa forma, fazem lembrar pequenos pães. ${ }^{8}$ Serão estes os «órgãos espumosos» referidos no texto inicial? órgãos de quê? De quem? Os "possíveis órgãos" encontram-se distribuídos por diversas superfícies retangulares, umas de plástico, outras de metal, outras de madeira, que se espalham por vários pontos do interior da casota (fig. 7 e 8). Parecem ter sido recolhidos e ali reunidos, como numa coleção. Um deles está por baixo de uma lupa de mesa (fig. 9). Talvez a sua visão ampliada nos possa esclarecer. Ao lado, encontramos um pequeno avião coberto de gesso e três esferas grandes, também de gesso - «ovos gigantes ou planetas minúsculos»? -. ${ }^{9}$ Por cima, pendurada na parede, quase como um quadro decorativo, o plano de uma tapeçaria com veados, numa paisagem florestal.

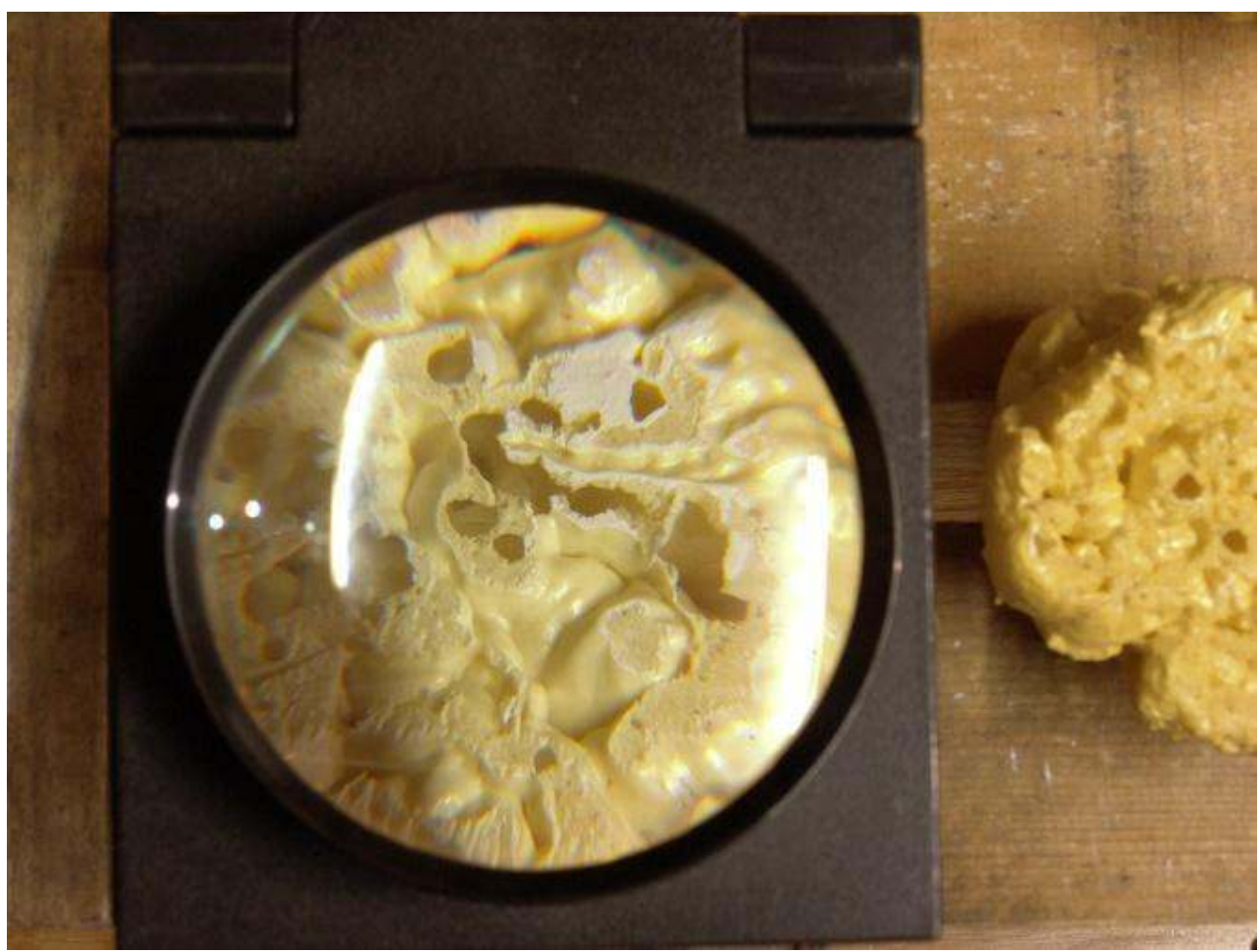

Fig. 9 - Oh la la na exposição Vidas Imaginárias, sede da FCG, entre novembro de 2004 e janeiro de 2005. Interior da "casota". Vista através da lupa que se encontra em cima da mesa de paletes.

Cortesia da artista (c) Susanne Themlitz

Dentro da casota encontramos ainda, espalhadas, fotografias onde faltam pedaços (recortados em circunferência) (fig. 10), tábuas de madeira pintadas e gafanhotos verdes de plástico. Numa porta, encostada a um dos lados, reúnem-se recortes de textos e fotocópias de fotografias, a preto e branco, nas quais foram removidas as cabeças de pessoas e animais. Noutras surgem rostos estranhos, distorcidos. 


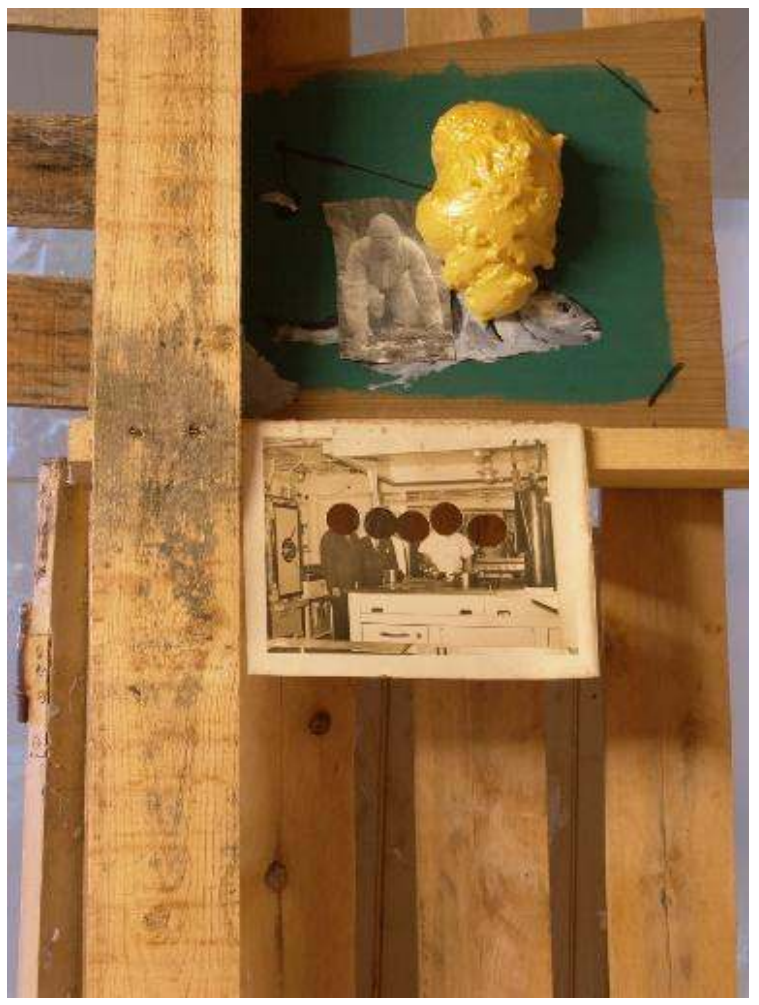

Fig. 10 - Oh la la na exposição Vidas Imaginárias, sede da FCG, entre novembro de 2004 e janeiro de 2005. Interior da "casota". Uma das fotografias que se encontra no interior da casota, na qual foram recortados os rostos das pessoas fotografadas.

Cortesia da artista ( ) Susanne Themlitz

Saímos da casota e "nas traseiras" encontramos um balde-chuveiro com vestígios da substância amarela, que vimos em montinhos no interior da casota. Esta espalha-se também num escadote verde e num dinossauro que, colocado sobre "andas" (com ripas de madeira) está encostado à parede (fig. 11). 


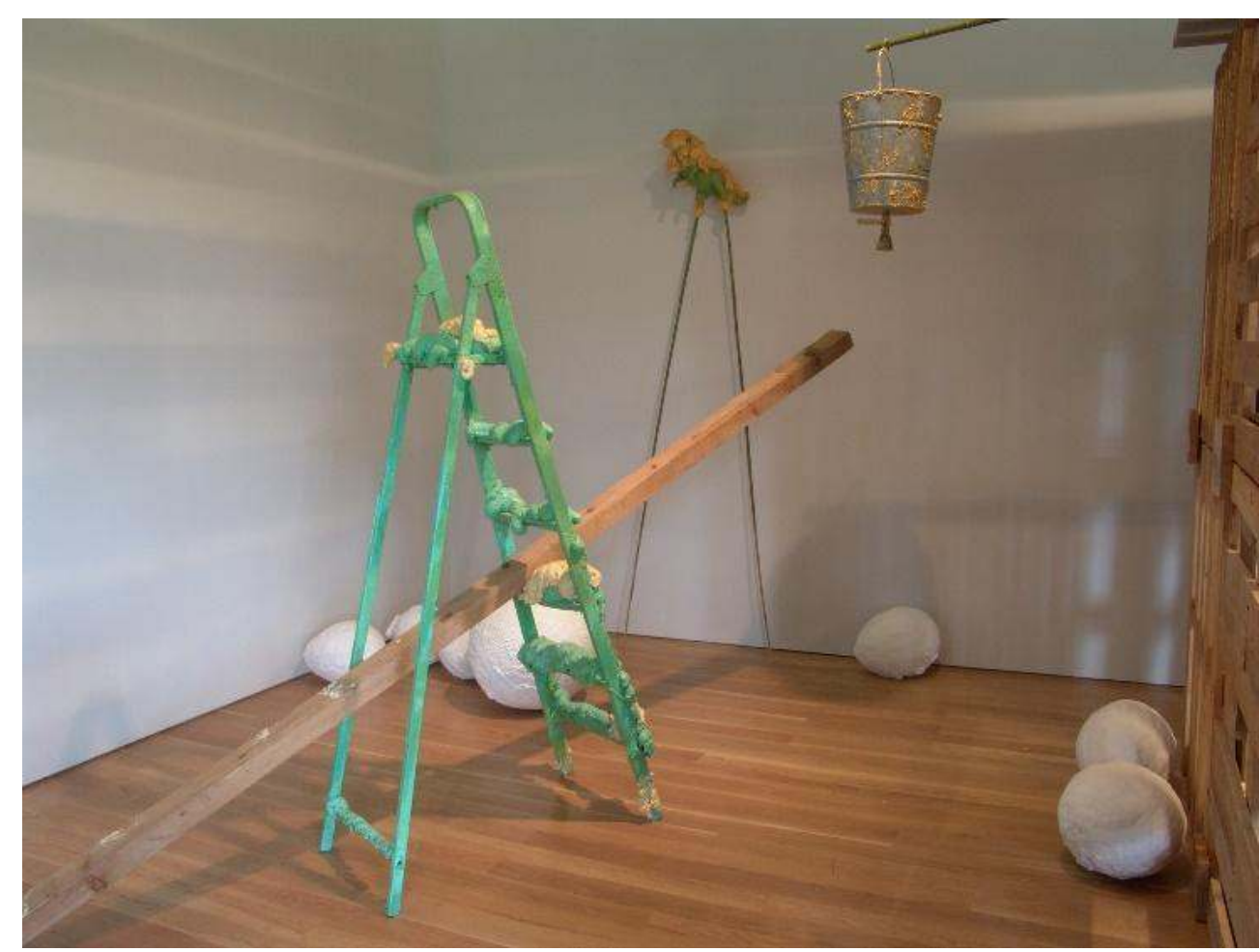

Fig. 11 - Oh la la na exposição Vidas Imaginárias, sede da FCG, entre novembro de 2004 e janeiro de 2005. Vista das traseiras da "casota" que inclui o escadote "verde", o "balde-chuveiro" esferas de gesso e o "dinossauro sobre andas" encostado à parede.

Cortesia da artista (c) Susanne Themlitz percurso. Talvez tentemos agora recordar o que vimos, reunir as pistas que estes vestígios nos dão. Talvez relembrar o texto que encontrámos à entrada. Reconhecemos agora as pistas que este nos dá, mas o enigmático «ou...» com que termina, assombra-nos. É o mesmo «ou» que divide as múltiplas teorias que fomos criando ao longo do percurso e que não conseguimos resolver.

31 Como referimos inicialmente, depois da exposição Vidas Imaginárias, a obra Oh la la foi adquirida pela Fundação Caixa Geral de Depósitos, integrando a sua coleção de arte contemporânea. A obra permaneceu nas embalagens criadas depois da exposição até 2008. Quando foi finalmente desembalada, a gestão da coleção tinha sido, entretanto, transferida para a Culturgest ${ }^{10}$ (em 2006). Os membros da equipa mais diretamente ligados à sua gestão diária ${ }^{11}$ não tinham assistido à exposição de 2005 , tendo apenas acesso a algumas fotografias, para tentar perceber a localização dos 230 elementos na obra. O trabalho de inventariação dos seus componentes iniciou-se, naturalmente, envolto em dúvidas. Só em 2009, durante a investigação no âmbito de um estágio académico, ${ }^{12}$ através da procura exaustiva de informações acerca da obra e da colaboração com a artista, foi possível identificar a maioria dos elementos (embora tenham permanecido algumas dúvidas) e criar uma sequência de inventariação que refletisse a sua organização na obra durante a primeira exposição. Desta forma, procurou criar-se alguma ordem no caos de baldes, garrafões de plástico cortados, caracóis, pedaços de musgo, etc. No entanto, como analisaremos, essa ordem acabaria por ter uma vida breve.

Em 2013 surgiu a oportunidade de voltar a mostrar a obra, integrando-a na exposição Sentido em Deriva - Obras da Coleção da Caixa Geral de Depósitos, ${ }^{13}$ tendo sido Oh la la 
apresentada nas galerias da Culturgest, em Lisboa. Instalar uma obra tão complexa, quase dez anos depois da sua primeira e única apresentação, revelou-se um exercício de rememoração por parte da artista. Tal como havia referido que faria no caso de uma nova apresentação ${ }^{14}$ Themlitz utilizou as fotografias da primeira exposição como base para repor a obra. Contudo, a reinstalação funcionou também como um momento de reencontro com o trabalho, que permitiu a ponderação de determinados aspetos. Mais do que esclarecer as dúvidas que restavam no trabalho de inventariação feito anteriormente, a nova exposição da obra obrigou a um novo processo de inventariação, ou a um reajustamento deste, uma vez que, nesta segunda apresentação, a obra sofreu diversas alterações relativamente à primeira.

Apesar de o espaço, em 2013, ter uma área e formato semelhantes ao da primeira exposição, permitindo mostrar a peça completa, a disposição dos elementos não foi exatamente igual. Themlitz não trazia um plano definido para a sua colocação, apesar de ter tido acesso às dimensões da sala. Foi no próprio espaço de exposição que a artista decidiu a colocação dos diversos elementos, alguns dos quais tiveram várias localizações antes da final.

O conjunto que incluía a "bicicleta voadora" era demasiado alto para o pé direito da sala da galeria da Culturgest utilizada. Na exposição na FCG tinha sido necessário retirar parte do teto para que este elemento coubesse no espaço. Na segunda apresentação da obra, optou-se por trocar o andaime que suportava a bicicleta por outro mais baixo, que antes se incluía noutro conjunto (fig. 12). Este, por sua vez, ganhou dimensões bastante superiores e acabou por incluir as esferas de gesso que, na primeira exposição, se encontravam nas traseiras da casota (fig. 13).

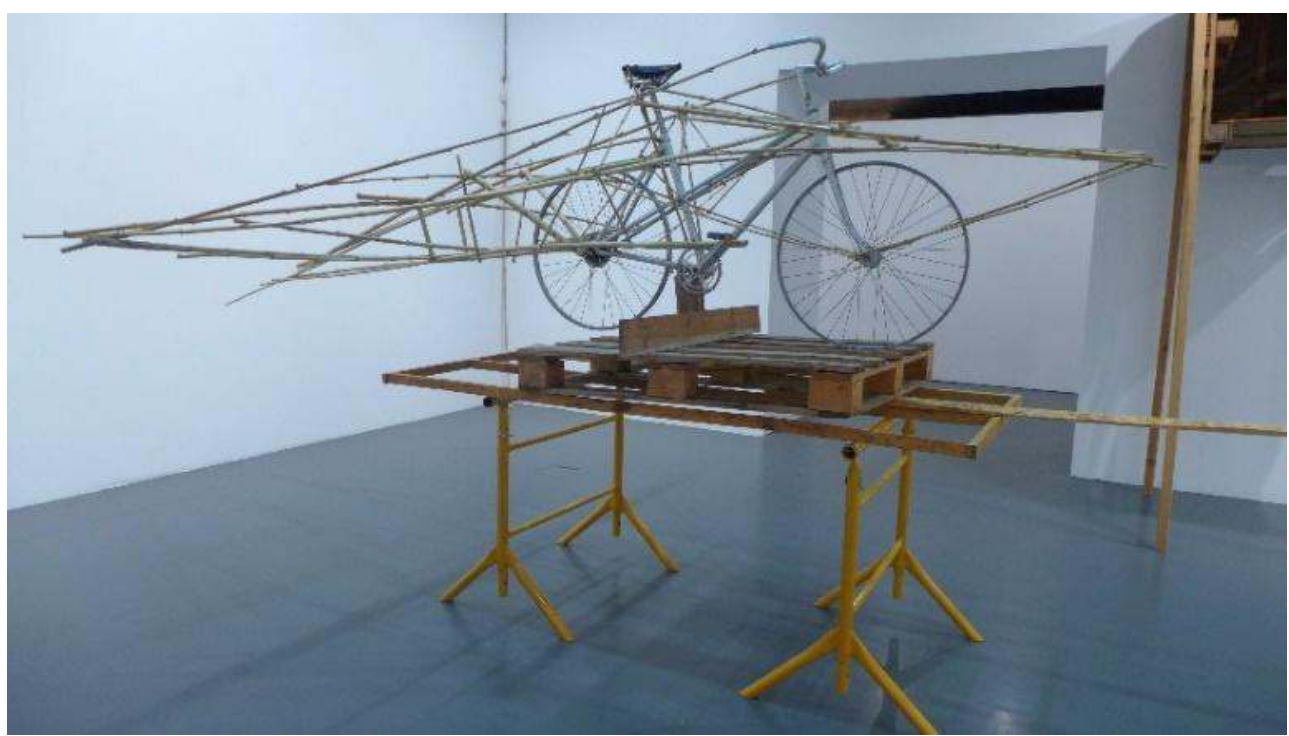

Fig. 12 - Oh la la na exposição Sentido em Deriva - Obras da Coleção da Caixa Geral de Depósitos, Galeria da Culturgest, Lisboa, entre outubro de 2013 e janeiro de 2014. Elemento da "bicicleta voadora" reconfigurado sobre um andaime mais baixo.

Fotografia de Cristina Barros Oliveira 


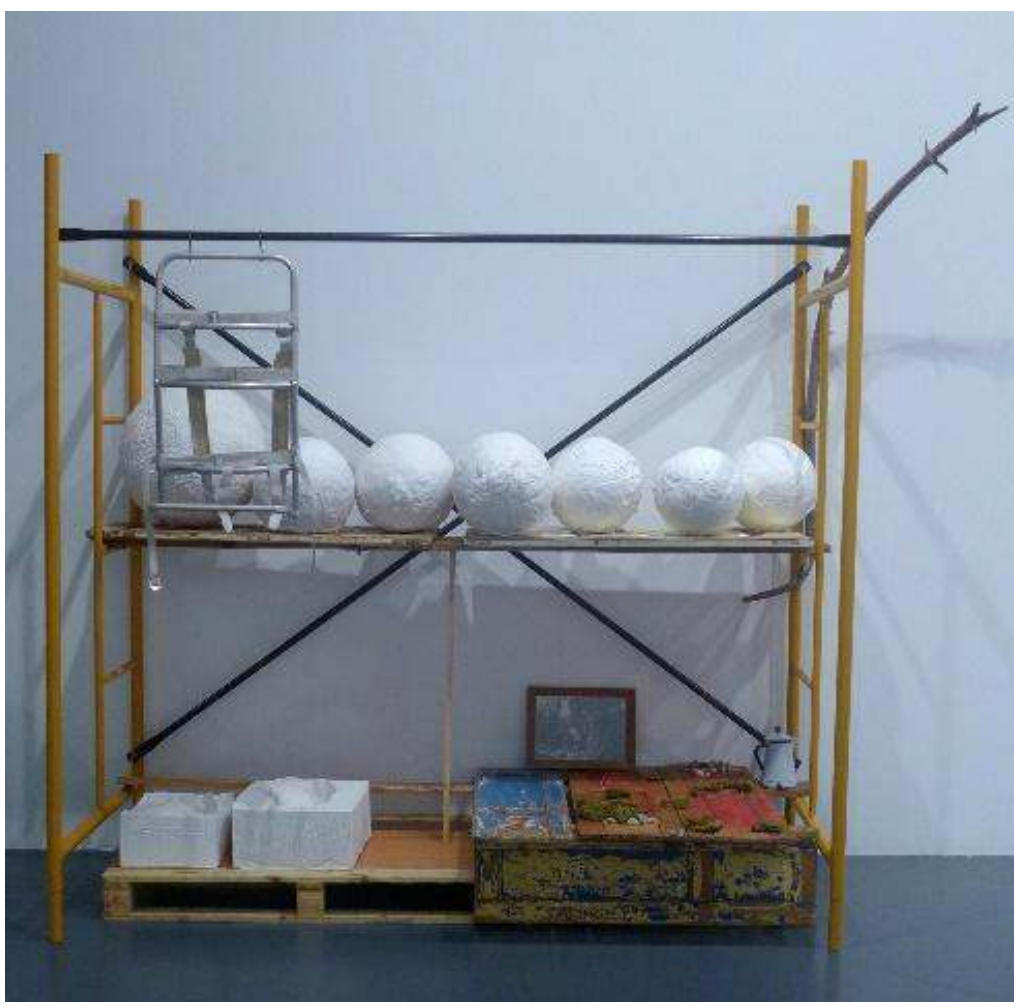

Fig. 13 - Oh la la na exposição Sentido em Deriva - Obras da Coleção da Caixa Geral de Depósitos, Galeria da Culturgest, Lisboa, entre outubro de 2013 e janeiro de 2014.

Fotografia de Cristina Barros Oliveira

Ou seja, a necessidade de alteração de um componente levou à alteração de três. Segundo a artista, embora tivesse tido conhecimento do problema anteriormente, só na altura da montagem soube como resolvê-lo. ${ }^{15}$

A montagem da "casota" implicou a introdução de novas paletes de madeira, dado ser insuficiente o número existente na coleção. Talvez a casota tenha adquirido maiores dimensões desta vez - dado que não havia instruções para a sua construção - ou algumas paletes tenham desaparecido durante as transferências de Oh la la. Um dos elementos da peça - o dinossauro que se encontrava nas traseiras da casota - foi removido da obra pela artista, possivelmente de forma permanente. Em entrevista, Themlitz afirmou que já na primeira exposição estava hesitante em relação àquele elemento, algo que se acentuou desta vez, acabando por decidir removê-lo. ${ }^{16}$

Os conjuntos que tinham sido definidos a partir da posição dos elementos na primeira apresentação da obra, e utilizados como base para a numeração no processo de inventariação foram, deste modo, modificados. A lógica criada no processo de inventariação perdeu-se.

Outra modificação prendeu-se com o tipo de plantas utilizadas. As couves galegas, que tinham uma presença expressiva na primeira apresentação da obra, foram eliminadas e substituídas por catos do tipo Opuntia ficus (também conhecido por piteira, figo do diabo, figueira da Índia, entre outros), recolhidos nas zonas de Sintra e de Cascais. Esta alteração deveu-se à experiência na FCG, onde as couves não se adaptaram ao novo ambiente, desenvolvendo fungos, que deram às plantas um aspeto amarelecido e pouco saudável. ${ }^{17}$ Considerando que a presença de plantas "doentes" perturbaria a leitura da obra "porque fungos espalhados em couves numa instalação é um conteúdo» ${ }^{18}$ - Themlitz 
optou por trocar as couves pelos catos, que teriam provavelmente uma maior resistência (fig. 14). A menção às couves que surgia no texto inicial da instalação acabou por ser alterada e substituída por «catos».

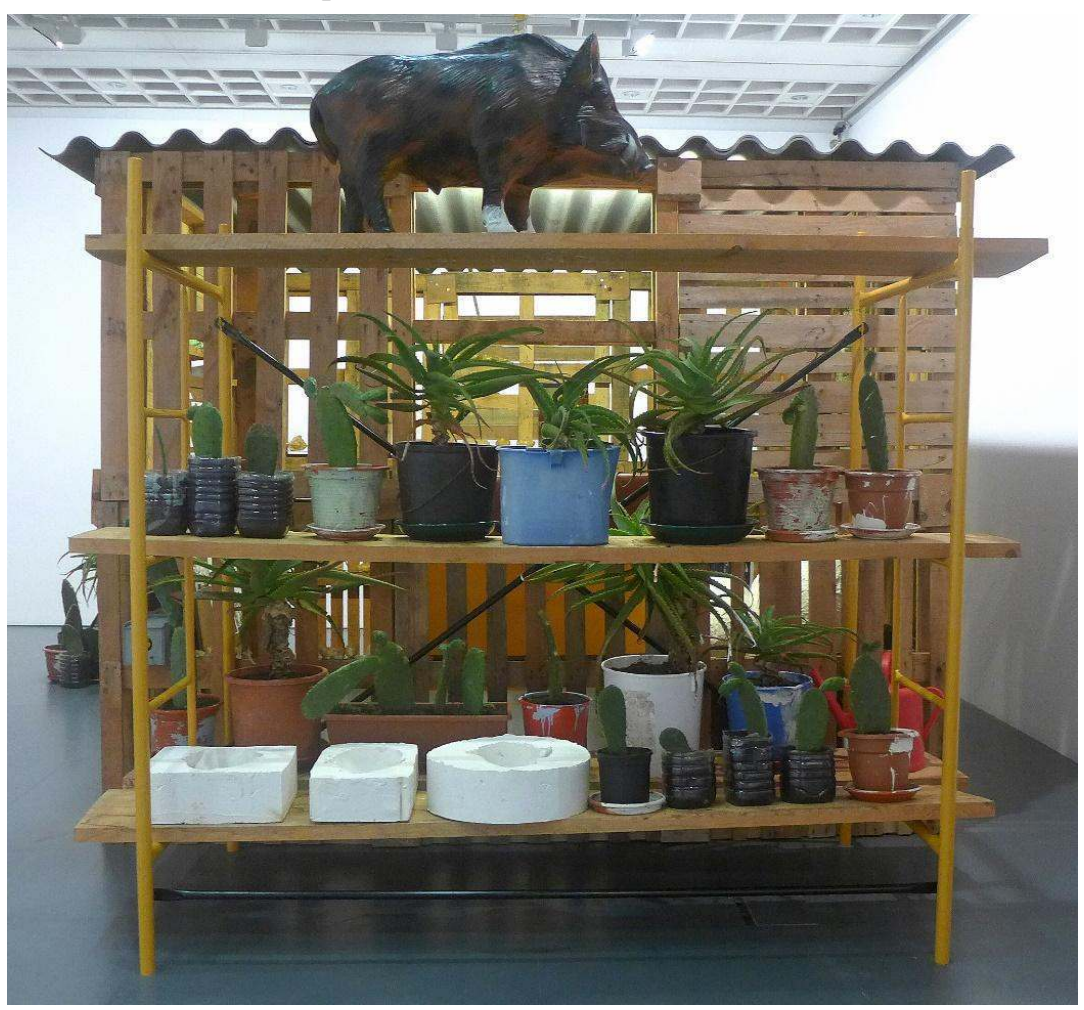

Fig. 14 - Oh la la na exposição Sentido em Deriva - Obras da Coleção da Caixa Geral de Depósitos, Galeria da Culturgest, Lisboa, entre outubro de 2013 e janeiro de 2014. Vista da lateral da "casota de paletes". No andaime figuram apenas catos não sendo utilizadas couves como na primeira exposição.

Fotografia de Cristina Barros Oliveira

Embora sejam idênticos em termos de formato, os espaços utilizados, na primeira e segunda exposição, são bastante distintos entre si, afetando, de modos diferentes, a perceção de Oh la la. A ligação com o jardim que existia na FCG - e que, como vimos, inspirou a artista na criação da obra - perdeu-se na segunda apresentação. $O$ espaço totalmente fechado, de paredes brancas e chão cinzento das galerias da Culturgest, contrastava bastante com a sala de paredes rasgadas ao exterior e chão de madeira, do edifício-sede da FCG.

Para Themlitz, o novo espaço conferiu à obra uma «tranquilidade» que não existia na primeira apresentação. Por um lado, eliminou-se o «ruído» criado pela presença do jardim e, por outro, deixou de haver uma ligação cromática entre a peça e o chão de madeira: «era tudo muita madeira, era tudo muito orgânico, muito cinzento». ${ }^{19}$ No entanto, a artista admite que, embora desta vez «talvez tenha gostado mais assim», também tinha ficado bastante satisfeita com a apresentação na FCG. Para Themlitz «a peça vai ganhando conforme se vai podendo mostrar em vários sítios» sendo difícil afirmar o que gostou mais ou menos. É sobretudo interessante ver que «consegue ganhar outra força em espaços diferentes». ${ }^{20}$ Themlitz chegou mesmo a afirmar que seria ideal «poder-se, com instalações deste tipo, fazer um estudo de cinco situações arquitetonicamente completamente diferentes». ${ }^{21} \mathrm{~A}$ artista entende as várias apresentações da obra como uma continuação do processo criativo. No fundo, um testar 
das diversas possibilidades que esta oferece, nomeadamente no confronto com diferentes espaços. ${ }^{22}$

41 Durante a montagem de Oh la la, em 2013, foi possível testemunhar a interação entre Themlitz e os membros da equipa envolvida na concretização da exposição. Algumas destas interações tiveram influência sobre a apresentação da obra como, por exemplo, no caso da opção escolhida para a forma de expor do texto da autoria da artista, que integra a instalação. Na primeira exposição da obra, este texto foi colado sobre a parede com letras autocolantes. Em 2013, a decisão acabou por ser tomada, durante a montagem da obra, numa conversa entre a artista e Mário Valente, coordenador de produção e exposições na Fundação CGD - Culturgest.

Quando o coordenador abordou a artista acerca da forma de expor o texto, a primeira resposta de Themlitz foi sugerir fotocopiá-lo e colá-lo na parede, algures no espaço da instalação. Durante a conversa com Mário Valente foram discutidas diversas hipóteses em torno do tamanho da letra e do formato do papel, tendo em conta a facilidade de leitura pelo público e a necessidade de que o texto estivesse escrito em duas línguas. Apesar de fazer parte da obra, por sugestão de Valente, o texto acabou por ter o formato de tabelas da exposição, que foram coladas sobre uma base de $k$-line, ${ }^{23}$ passando a incluir duas páginas para permitir acomodar o texto num tamanho de letra maior do que aquele em que se encontrava. Seguiu-se uma discussão acerca da sua localização. Themlitz sugeriu uma das paredes da entrada da sala, e Valente sugeriu a parede contrária, justificando com o percurso do público e a relação com a obra que se encontrava exposta na sala anterior. Foi clara a influência das propostas do coordenador de produção que, embora com o acordo da artista, alteraram a sua opção inicial: de uma para duas folhas, um tamanho de letra diferente, uma localização diferente e uma forma de afixar também distinta.

Uma situação semelhante, embora menos visível, na mesma obra prendeu-se com a forma como foi montada a "torre de alguidares". Na exposição anterior, um dos visitantes, acidentalmente, derrubou a torre com uma mochila. De forma a evitar acidentes, na exposição de 2013 foi colocado um varão roscado a unir todos os alguidares, pelo interior. Esta decisão resultou de uma conversa entre a artista e a equipa de montagem, tendo a sugestão partido de um dos elementos da última.

Embora estas mudanças na obra não sejam muito marcantes no seu todo, e a artista tenha autorizado todas as decisões tomadas, as alterações que relatámos parecem-nos, ainda assim, exemplificar as formas como o envolvimento de várias pessoas, para além do artista, na instalação da obra pode influenciar o resultado final. A nossa não é, aliás, a única investigação que destaca a interferência de outros agentes, para além do artista, no percurso de uma instalação, tendo sido esta uma questão também referida por autores como Saaze (2011), Philips (2015), Yaneva (2003) ou Irvin (2006).

Para além da influência que os diálogos entre o artista e a equipa do museu podem ter nas suas opções, é inevitável que, ao tomarem decisões pelo artista, quando este não está presente (nomeadamente as que se prendem com a escolha de novos espaços de apresentação e a adaptação das obras aos mesmos) os agentes envolvidos na montagem das instalações introduzam alterações. Por outras palavras, o resultado final de uma manifestação de uma instalação não depende apenas do artista, mas daqueles que, com ou sem a presença deste, virão a ser responsáveis pela sua concretização. Apesar deste aspeto, como vimos, ser reconhecido no campo teórico, na prática a musealização de instalações tende a não o ter em consideração, por exemplo, ao nível da produção de 
documentação. Embora algumas propostas prevejam registos mais detalhados no que toca a estes aspetos ${ }^{24}$, tendencialmente a documentação das obras não inclui todos os participantes em cada uma das suas montagens, nem uma análise do seu impacto no resultado final. No entanto, quando as decisões envolvidas na reinstalação da obra passam a ser responsabilidade do museu, é vantajoso ter acesso a informações mais detalhadas, que permitam perceber a origem das opções em determinadas apresentações, nomeadamente por quem e porquê foram tomadas, podendo, a partir dessa base justificar as deliberações em apresentações futuras. É necessário por isso criar espaço na documentação para o esclarecimento destas informações.

\section{Considerações finais}

A biografia de uma instalação, tal como acontece com a biografia de uma pessoa, é feita de encontros, acasos, mudanças de opinião e novas aprendizagens que determinam o seu percurso. Todos estes fatores estão presentes no caso de Oh la la. As alterações ocorridas entre a primeira e a segunda apresentações tiveram origens diversas. Para além da modificação na aparência do espaço e do seu impacto sobre a perceção da obra, aprendizagens recolhidas na primeira exposição conduziram à substituição das couves por catos, a passagem do tempo levou à tomada de decisões diferentes, culminando na remoção de elementos, como o caso do dinossauro, constrangimentos nas dimensões do local de exposição levaram à alteração da disposição de diversos componentes e a participação de outros intervenientes, para além da artista, influenciou algumas opções, como analisámos anteriormente.

Todos estes fatores permitem entender a obra na sua totalidade, o seu percurso e o porquê de determinadas alterações. Estas pistas permitirão às gerações futuras tomar decisões informadas no que toca a preservação da obra, à medida que deixa de ser possível consultar o artista e todas as decisões de conservação e apresentação passam a ficar totalmente a cargo do museu.

Para além da documentação interna das instituições, dever-se-á, quanto a nós, construir uma prática distinta de divulgação da instalação e da informação que lhe diz respeito. Apesar da sua variabilidade, estas obras tendem a surgir, particularmente aos olhos do público, como entidades estáticas. Estas são geralmente associadas a uma determinada data ou datas, correspondentes ao "período de criação", quer na "etiqueta", durante a exposição, quer nos catálogos, onde muitas vezes não aparece sequer indicado o contexto (exposição, local, etc.) no qual foi captada a imagem da obra. 0 título, uma ou outra fotografia, normalmente da mesma apresentação, a data e, por vezes, uma lista de materiais e a expressão «dimensões variáveis» é toda a informação que, de uma forma geral, se encontra. A história ou, diríamos, a biografia da instalação, e os fatores que influenciaram o seu percurso, cuja análise permitiria uma compreensão mais global da obra, perdem-se, ficando esta, deste modo, presa a um presente sem memória.

\section{Agradecimentos}

Gostaríamos de agradecer a Susanne Themlitz a disponibilidade para participar nesta investigação, quer através da entrevista, quer pela cedência de muitas das imagens utilizadas. Agradecemos também à equipa da Culturgest, particularmente a Isabel Corte- 
Real e a Maria Manuel Benvindo, pela colaboração, disponibilidade e pelo convite para acompanhar a montagem da obra. Por fim, a Susana França de Sá com quem desenvolvi parte desta investigação.

\section{BIBLIOGRAFIA}

Appadurai, Arjun, ed. 1988. The Social Life of Things: Commodities in Cultural Perspective. Cambridge: Cambridge University Press.

Bishop, Claire. 2005. Installation Art: A Critical History. London: Tate Publishing.

França de Sá, Susana, Filomena Macedo, e Rita Macedo. 2015. "Da Teoria à Prática- Problemáticas em Torno da Preservação da Instalação Oh la la,... Oh la Balançoire/Microcosmos Tentacular (2003-04) de Susanne Themlitz." Museologia e Patrimônio - Revista Eletrônica do Programa de Pós-Graduação em Museologia e Patrimônio - Unirio 8 (1): 30-52.

Hoskins, Janet. 2006. “Agency, Biography and Objects.” In Handbook of Material Culture, 74-84. London: SAGE Publications Ltd.

Irvin, Sherri. 2006. "Museums and the Shaping of Contemporary Artworks." Museum Management and Curatorship (Thinking about Museums: Philosophical Perspetives) 21 (2): 143-156.

Mechelen, Marga van. 2006. “Experience and Conceptualization of Installation Art." http:// collections.europarchive.org

Medeiros, Margarida. 2002. "Susanne S. D. Themlitz" (entrevista). http:// www.susannethemlitz.net/index.php/Margarida_Medeiros.html

Molder, Jorge. 2004. “Vidas Imaginárias.” In Vidas Imaginárias, 4-7. Lisboa: Fundação Calouste Gulbenkian/Centro de Arte Moderna José de Azeredo Perdigão.

Oliveira, Cristina Barros. 2016. “A Instalação em Âmbito Museológico. Desafios e Estratégias para o Futuro.” Tese de doutoramento em História da Arte, vertente de Museologia e Património Artístico, Universidade Nova de Lisboa.

Oliveira, Nicolas de, Nicola Oxley, Michael Petry, e Michael Archer. 1994. Installation Art. London: Thames \& Hudson.

Phillips, Joanna. 2015. "Reporting Iterations: A Documentation Model for Time-based Media art." Revista de História da Arte (Performing Documentation in the Conservation of Contemporary Art) 4: 168-79.

Pugliese, Marina, e Barbara Ferriani. 2009. "Preserving Installation Art: Hypothesis for the Future of a Medium in Evolution. In Art Conservation and Authenticities. Material, Concept, Context, ed. Erma Hermens, e Tina Fiske, 174-82. London: Archetype Publications.

Ran, Faye. 2009. A History of Installation and the Development of New Art Forms: Technology and the Hermeneutics of Time and Space in Modern and Postmodern Art from Cubism to Installation. New York: Peter Lang.

Real, William. 2001. "Toward Guidelines for Practice in the Preservation and Documentation of Technology-based Installation Art." Journal of the American Institute for Conservation 40 (3): 211-231. 
Reiss, Julie. 1999. From Margins to Center: The Spaces of Installation Art. Londres: MIT Press.

Rosengarten, Ruth. 2008. "Uma História Natural da Sonolência.” In Estado do Sono, 25-36. Lisboa: Culturgest - Caixa Geral de Depósitos.

Rosenthal, Mark. 2003. Understanding Installation Art: From Duchamp to Holzer. Munique: Prestel.

Saaze, Vivian van. 2009. "From Intention to Interaction: Reframing the Artist's Interview in Conservation Research." In Art d'Aujourd'hui, Patrimoine de Demain - Conservation-Restauration des Ouvres Contemporaines, 20-28. Paris: SFIIC (Section Française de l'Institut International de Conservation).

Saaze, Vivian van. 2011. "Going Public: Conservation of Contemporary Artworks: Between Backstage and Frontstage in Contemporary Art Museums." Revista de História da Arte 8: 235-49.

Scholte, Tatja. 2011. "Introduction." In Inside Installations. Theory and Practice in the Care of Complex Artworks. Tatja Scholte e Glenn Wharton, 11-20. Amsterdam: Amsterdam University Press.

Stringari, Carol. 1999. "Installations and Problems of Preservation." In Modern Art: Who Cares? ed. Ijsbrand Hummelen, e Dionne Sillé, 272-281. Amsterdam: Foundation for the Conservation of Modern Art/Netherlands Institute for Cultural Heritage.

Themlitz, Susanne. 2009. Entrevista conduzida por Susana França de Sá a 30 de outubro de 2009. Material não publicado.

Themlitz, Susanne. 2009. Entrevista conduzida por Susana França de Sá a 17 de novembro de 2009. Material não publicado.

Themlitz, Susanne. 2014. Entrevista conduzida por Cristina Barros Oliveira e Susana França de Sá a 5 de março de 2014. Material não publicado.

Vall, Renée van de, Hanna Hölling, Tatja Scholte, e Sanneke Stigter. 2011. "Reflections on a Biographical Approach to Contemporary Art Conservation." In ICOM-CC: 16th Triennial Conference. Lisboa: [s.n.]. http://dare.uva.nl/record/434262

Wandschneider, Miguel. 2006. "Susanne Themlitz: O Estado do Sono." Texto do jornal da exposição $O$ Estado do Sono, (s/p). www.culturgest.pt/docs/themlitz.pdf

Weyer, Cornelia. 2006. "Restoration Theory Applied to Installation Art.” VDR Beiträge 2: 40-48.

Wharton, Glenn, e Harvey Molotch. 2009. “The Challenge of Installation Art.” In Conservation: Principles, Dilemmas and Uncomfortable Truths, Alison Richmond, e Alison Bracker, 210-22. Oxford: Butterworth-Heinemann e Victoria and Albert Museum.

Yaneva, Albena. 2003. "When a Bus Met a Museum: Following Artists, Curators and Workers in Art Installation.” Museum \& Society 1 (3): 116-31.

\section{NOTAS}

1. Este artigo tem origem em parte da investigação realizada durante a nossa tese de doutoramento (Oliveira 2016), que contou com o apoio da Fundação para a Ciência e Tecnologia. Relaciona-se também com os resultados do projeto de investigação "Documentação da Arte Contemporânea" (PTDC/EAT-MUS/114438/2009) desenvolvido pelo Instituto de História da Arte da Universidade Nova de Lisboa.

2. New Strategies in the Conservation of Contemporary Art resultou de uma colaboração entre a Universidade de Maastricht, a Universidade de Amsterdão e o Instituut Collectie Nederland, com financiamento parcial da Nederlandse Organisatie voor Wetenschappelijk Onderzoek e foi 
coordenado por Renée van de Vall. Este projeto procurou explorar os aspetos teóricos e éticos da conservação de arte contemporânea.

3. Entre os autores citados neste artigo encontram-se Appadurai (1988) e Hoskins (2006).

4. Citações do texto da autoria de Susanne Themlitz que se inclui na obra.

5. Citações do texto da autoria de Susanne Themlitz que se inclui na obra.

6. Susanne Themlitz, entrevista conduzida por Susana França de Sá a 17 de novembro de 2009, material não publicado.

7. A descrição da obra que aqui se apresenta pretende reconstruir o percurso e uma possível experiência de um espectador hipotético, relatada na primeira pessoa, tendo em conta a distribuição dos diversos elementos pelo espaço.

8. São na verdade estruturas conseguidas através do enrijecimento de espuma de poliuretano.

9. Citação do texto da autoria da artista que se inclui na instalação.

10. Fundação CGD - Culturgest, a partir de 2008.

11. Nomeadamente Isabel Corte-Real (conservadora da coleção) e Maria Manuel Conceição (responsável pela conservação preventiva).

12. Este estágio, pela aluna Susana França de Sá, correspondeu às disciplinas de Projeto I e Projeto II do curso de mestrado em Conservação e Restauro da Faculdade de Ciências e Tecnologia da Universidade Nova de Lisboa. Os resultados deste trabalho deram origem à publicação do artigo «Da Teoria à Prática - Problemáticas em Torno da Preservação da Instalação Oh la la,... Oh la Balançoire/Microcosmos Tentacular (2003-04) de Susanne Themlitz» (França de Sá, Macedo, e Macedo 2015).

13. A exposição teve lugar nas galerias da Fundação Caixa Geral de Depósitos - Culturgest em Lisboa e no Porto, com uma exposição, em Lisboa, entre 12 de outubro de 2013 e 12 de janeiro de 2014, e com a apresentação de uma peça por semana no Porto, a partir de 22 de outubro. A curadoria ficou a cargo de Bruno Marchand.

14. Em entrevistas anteriores com Susana França de Sá (não publicadas).

15. Susanne Themlitz, entrevista conduzida por Cristina Barros Oliveira e Susana França de Sá a 5 de março de 2014, material não publicado.

16. Ibid.

17. A causa da inadaptação das plantas é desconhecida. Embora tenha sido sugerido pelos funcionários da FCG que o problema poderia ser o ar condicionado, outros fatores poderão ter levado ao amarelecimento das plantas e desenvolvimento de fungos, por exemplo: ausência de luz direta, rega excessiva, as plantas poderiam já estar contaminadas, entre outros. No entanto, se houvesse possibilidade de manter as couves saudáveis, Themlitz não teria trocado as plantas (Susanne Themlitz, entrevista conduzida por Cristina Barros Oliveira e Susana França de Sá a 5 de março de 2014, material não publicado).

18. Susanne Themlitz, entrevista conduzida por Cristina Barros Oliveira e Susana França de Sá a 5 de março de 2014, material não publicado.

19. Susanne Themlitz, entrevista conduzida por Cristina Barros Oliveira e Susana França de Sá a 5 de março de 2014, material não publicado.

20. Ibid.

21. Susanne Themlitz, entrevista conduzida por Susana França de Sá a 30 de outubro de 2009, material não publicado.

22. Susanne Themlitz, entrevista por Cristina Barros Oliveira e Susana França de Sá, 5 de março de 2014, material não publicado.

23. O material conhecido geralmente por k-line é frequentemente utilizado para a construção de maquetas e outros trabalhos manuais. É constituído por uma placa de esponja de polietileno entre duas placas de cartolina branca.

24. Por exemplo, a proposta apresentada por Phillips (2015). 


\section{RESUMOS}

Partindo da análise do percurso da instalação Oh la la,... oh la Balançoire/Microcosmos Tentacular ( 2004-2013; coleção Caixa Geral de Depósitos), da artista portuguesa Susanne Themlitz (n. 1968), este artigo explora algumas das formas como as instalações se alteram ao longo do tempo, a cada nova apresentação. Estas transformações, cujas origens podem ser diversas, desafiam a ideia de estaticidade da obra de arte, obrigando a uma mudança na forma como o museu desenvolve, quer as estratégias de conservação, quer os modos de comunicação da obra ao público. A biografia de Oh la la, que neste artigo se apresenta, constrói-se no cruzamento das informações documentais com aquelas obtidas junto dos diversos intervenientes na vida desta instalação, não só através de entrevistas, mas da observação do processo de montagem da obra e das discussões que estiveram na base de certas decisões. Concluímos que a ideia de biografia pode ser fundamental para o entendimento do percurso da obra e das relações que foi traçando não só com diferentes espaços, mas também com distintos momentos da carreira do artista ou até com outros intervenientes na "vida" da obra.

Examining the case of the installation Oh la la,... oh la balançoire/Microcosmos Tentacular (2004-2013, Caixa Geral de Depósitos collection.) by the Portuguese artist Susanne Themlitz (born 1968), this paper addresses some of the ways in which installations change each new presentation. These transformations demand new strategies of conservation as well as new ways for the museum to communicate with the audience. The biography of the art installation Oh la la that is presented in this paper is constructed crossing documental information with information collected with several actors that have intervene in the life of the art installation, not only through interviews, but also by observing its mounting process and following the discussions behind every decision about it. We conclude that the notion of biography contributes to a better understanding of the artwork's path, how it adapts to different spaces and how it relates to different moments in the artist's career or even other actors in the artwork's "life".

\section{ÍNDICE}

Keywords: museum, installation art, object biography, contemporary art conservation, Susanne Themlitz

Palavras-chave: museu, instalação, biografia de objeto, conservação arte contemporânea, Susanne Themlitz

\section{AUTOR}

\section{CRISTINA BARROS OLIVEIRA}

Doutorada em História da Arte, na vertente de Museologia e Património Artístico, na Faculdade de Ciências Sociais e Humanas da Universidade de Lisboa, com a tese A Instalação em Âmbito Museológico: Desafios e Estratégias para o Futuro (2016). Licenciada em Conservação e Restauro pela 
Faculdade de Ciências e Tecnologia da Universidade Nova de Lisboa onde obteve também o mestrado, especializando-se na preservação de instalações artísticas. É membro colaborador do Instituto de História da Arte da Universidade Nova de Lisboa, na linha de Museum Studies.

Instituto de História da Arte, Faculdade de Ciências Sociais e Humanidades da Universidade Nova de Lisboa, Av. de Berna, 26-C, 1069-061 Lisboa, Portugal, mcristinabo@gmail.com 